\title{
Que se de diferente modo al gobierno de las Indias, que se van perdiendo muy a prisa. Arbitrismo y administración a principios del siglo XVII/
}

\author{
Que se de diferente modo al gobierno de las Indias, \\ que se van perdiendo muy a prisa. Arbitrism and \\ Administration in the Early Seventeenth Century ${ }^{1}$
}

Arrigo Amadori

Universidad Complutense de Madrid

A pesar de que el arbitrismo era un elemento importante de la vida política hispánica del siglo XVII, la historiografía americanista no ha puesto demasiado énfasis en su estudio. Este artículo intenta resaltar la trascendencia de este género a través de la obra del arbitrista Manuel Gaytán de Torres. El objetivo consiste en trazar una aproximación a sus percepciones sobre la administración, la organización institucional americana y los principios que debían informar el ejercicio de los oficios, y a sus propuestas para revertir la compleja situación atravesada por el mundo hispánico en las primeras décadas del siglo XVII. Los escritos de Gaytán poseen un gran interés porque forman parte del movimiento reformista que se desarrolló durante el valimiento del conde-duque de Olivares y comparten bastantes puntos en común con el programa del favorito real.

Palabras ClaVE: Arbitrismo; Administración; Gobierno; Instituciones; Siglo XVII; Manuel Gaytán de Torres; Cultura Política; Historia Política.

Although arbitrismo was an important element in seventeenth-century Hispanic political life, Americanist historiography has not paid much attention to their study. This article proposes to underscore the importance of this type of literature through the work of Manuel Gaytan de Torres. It will aim to analyze his thoughts on public administration, American institutional organization, and the principles that should guide professional activities in the arts and crafts, as well as his proposals for the remedy of the complex situation in which the Hispanic world was immersed in the seventeenth century. Gaytan's works are interesting because they form part of the reform movement that developed under the influence of the royal favourite, Olivares, with whose general programme they have several common points in common.

KeYwords: Arbitrismo; Economic Reformism; Administration; Government; Institutions; Manuel Gaytan de Torres; Political Culture; Political History; Seventeenth Century.

1 Este artículo se enmarca dentro de las actividades del grupo de investigación complutense Organización del poder y redes sociales en la Historia de América (930371). Quisiera dejar constancia de mi agradecimiento a la profesora Pilar Ponce Leiva por sus comentarios y sugerencias, que me han resultado de gran provecho. 


\section{Crisis y arbitrismo: un género y su presencia en el contexto americano}

Durante los últimos años del reinado de Felipe II, Castilla comenzó a experimentar una serie de dificultades y reveses de distinta índole que parecieron sugerir a los contemporáneos el fin de una época excepcional, asentada en la proyección imperial, y el comienzo de otra marcada por un signo no tan favorable para la Monarquía hispana. Puede afirmarse que esos años no sólo constituyeron el inicio de un periodo crítico, jalonado por profundos cambios que habrían de operar durante largo tiempo sobre la realidad castellana, sino que, además, marcaron el comienzo de un movimiento en el que cierta parte de la sociedad adquirió una singular conciencia de su gravedad y de su trascendencia, asentándose la idea de declinación. Naturalmente, no es que no haya aflorado en otros tiempos la certeza de estar atravesando un periodo de decadencia. En este sentido, por ejemplo, en las primeras décadas del siglo XVII, el conde-duque de Olivares reconocía que aquella era una idea "que sin duda se debe de haber oído a cuantos viejos y malcontentos ha habido en el mundo después que Dios le crió". Pero los reveses militares, las dificultades de la Hacienda, la disminución de las remesas reales americanas, la situación de la Carrera de Indias, el desastroso panorama monetario o los problemas de subsistencia, pusieron a prueba todo un sistema de creencias y valores y dieron lugar a una profunda crisis de confianza y de expectativas que resquebrajó la mentalidad segura y dominante que había imperado hasta ese momento. ${ }^{2}$ Incluso, algunos autores y memorialistas llegaron a temer la fragmentación de las posesiones de Felipe IV, la pérdida de la preponderancia mundial de la Monarquía española, e incluso pusieron en duda su continuidad. Con el pasar de los años y la persistencia de las dificultades, se fue acentuando en la conciencia colectiva el tópico de la declinación, que en ocasiones dio paso al más absoluto abatimiento de las esperanzas de futuro. Es decir, no sólo fueron años en los que en Castilla se padeció un profundo declive, sino también un tiempo en el que se desarrolló una percepción aguda, angustiante y singular de la difícil situación que se estaba experimentando. ${ }^{3}$ Entre

2 John Elliott: "América y el problema de la decadencia española", Anuario de Estudios Americanos, XXVIII, Sevilla, 1971, p. 12.

3 Sobre la percepción de la decadencia, véase John Elliott: "Introspección colectiva y decadencia en España a principios del siglo XVII", en John Elliott (ed.): Poder y sociedad en la España de los Austrias, Madrid, Crítica, 1983, pp. 198-223. 
otras cosas, este fenómeno tuvo su expresión en el inusitado incremento de la cuantía y del nivel de la reflexión y de la crítica, que se concentró tanto en dilucidar las causas de la crisis, como también - y fundamentalmenteen proporcionar remedios para su superación. Así, hacia finales del reinado de Felipe III, la especulación y los debates políticos y económicos llegaron a convertirse en moneda corriente, no ya en los ámbitos intelectuales o cortesanos de la alta administración, sino también en las tabernas, en los teatros y en otros espacios de sociabilidad, ${ }^{4}$ conformando una incipiente opinión pública. Probablemente el indicador por excelencia de esta intensa compenetración de un sector de la población con las dificultades del Reino sea la proliferación de arbitrios sobre cuestiones económicas, sociales, fiscales, políticas, estratégicas o técnicas, presentados a las autoridades a lo largo de varias décadas.

El arbitrismo castellano fue un género que alcanzó un gran desarrollo desde las últimas décadas del siglo XVI y que se prolongó durante buena parte del XVII. Uno de sus rasgos característicos fue su marcada heterogeneidad, dada por la variada gama de temáticas y soluciones que trataba, por el horizonte intelectual desde el que abordaba la crítica o, incluso, por el talento, la capacidad, la formación o la información de los autores. ${ }^{5}$ Sin embargo, y más allá de esta peculiaridad, es posible hablar de un discurso arbitrista caracterizado por un lenguaje, un estilo de expresión y exposición, una estructura, una forma de argumentación y unos razonamientos específicos.

Por otra parte, como ha puntualizado Anne Dubet, el arbitrismo no sólo se compone de un discurso, sino que también supone unas prácticas y un ambiente político determinado que es importante tener presente para apreciar su verdadero significado en una sociedad de Antiguo Régimen. ${ }^{6}$ De hecho, no resultaría exagerado sostener que el arbitrismo resultó ser un componente significativo del desenvolvimiento de la compleja vida política hispana del siglo XVII.

Como es sabido, el arbitrista presentaba un escrito al rey por medio de los secretarios, los Consejos, los oficiales reales, el valido o las Cortes, con

4 Robert Stradling: Felipe IV y el gobierno de España, Madrid, Cátedra, 1989, p. 37.

5 Para una visión de conjunto sobre el arbitrismo, véase el clásico trabajo de Ignacio Gutiérrez Nieto: "El pensamiento económico, político y social de los arbitristas", en Historia de España, vol. XXVI: 1, Madrid, Espasa Calpe, 1988, pp. 233-351.

6 Anne Dubet: "Los arbitristas entre discurso y acción política. Propuestas para un análisis de la negociación política”, Tiempos Modernos (revista digital), 9, 2003, pp. 1, 2, 7-12. 
la intención de que sus propuestas fueran aceptadas y sus servicios — que así era como se entendía esta acción - se remuneraran. Por lo general, el acceso de estos autores a las instancias de decisión de la Monarquía dependía de sus vínculos personales, que solían actuar como nexos con sus potenciales valedores cortesanos, quienes en última instancia los promovían o los desechaban según sus motivaciones o intereses. Pero una vez que accedían a los espacios de debate y de toma de decisión, estos escritos podían llegar a desempeñar un papel clave. Dubet ha resaltado el hecho de que tanto los propios autores como sus proyectos muchas veces ocupaban un lugar central en la negociación de la Corona con grupos de intereses sectoriales o regionales, o en la elaboración de medidas - generalmente fiscales- por parte de las autoridades. Dentro de este último aspecto, no sólo las Juntas particulares, muy frecuentes entre 1621 y 1643, sino también el propio complejo polisinodal podía trabajar a partir de este tipo de escritos, configurando una "administración fiscal y financiera basada en gran parte en la colaboración con grupos e individuos privados". ${ }^{7}$

Durante las décadas de 1620 y 1630 hay una circunstancia fundamental que contribuye a explicar el gran desarrollo del arbitrismo y de su función política. La buena acogida dada por el conde-duque de Olivares a los arbitrios operó como un incentivo para que le fueran remitidos numerosos memoriales con proyectos de toda clase y naturaleza. ${ }^{8}$ En la práctica cotidiana, era habitual que él mismo actuara como intermediario entre los autores y la alta administración, o directamente como su valedor ante las instancias que debían intervenir en su consideración. Tal fue el caso del Consejo de Indias, al que Olivares solía encomendar que deliberase sobre arbitrios, generalmente de carácter fiscal. Asimismo, sabemos que tenía asesores de confianza a los que recurría para que sopesaran la utilidad de los arbitrios y que algunos personajes cercanos, como su confesor, el jesuita Hernando de Salazar, actuaban también como captadores de escritos.

Para el caso estrictamente castellano, este fenómeno ha concentrado la atención de los investigadores, que han ido variando y complejizando la interpretación que se tenía de él. Pero, curiosamente, se ha tendido a soslayar una de sus derivaciones que, aunque en principio parece haber tenido

7 Ibidem, pp. 9-11. Para la descripción de un proceso legislativo a partir de arbitrios, véase: Arrigo Amadori: "Privanza, patronazgo y fiscalidad indiana en la corte de Madrid durante el reinado de Felipe IV (1629-1631)", Revista Complutense de Historia de América, 34, Madrid, 2008, pp. 63-84.

8 Gregorio Marañón: El conde-duque de Olivares. La pasión de mandar [1933], Madrid, Espasa Calpe, 2006, pp. 150-155. 
menor envergadura, no dejó de tener cierta entidad e influencia. Me estoy refiriendo al arbitrismo sobre cuestiones indianas.

Probablemente, la razón fundamental de esta notable ausencia sea el hecho de que el Consejo de Indias, en lo que respecta a la época de los Austrias, no ha sido incluido dentro de la renovación historiográfica experimentada por la Historia Política en el ámbito cortesano. Esta circunstancia, a su vez, no es más que otra manifestación de la larga disociación en la que hasta hace poco tiempo han permanecido el modernismo español y el americanista, que constituye más el resultado de la imposición de circunstancias exógenas que de criterios científicos. Por estas razones, una característica común a la gran mayoría de los estudios dedicados a este sínodo en este periodo es su enfoque marcadamente institucionalista, que ha tendido a soslayar, entre otras cosas, la gran complejidad de las dinámicas internas del Consejo, la incidencia de los vínculos interpersonales y la capilaridad en los procesos de elaboración de las disposiciones americanas. ${ }^{9}$

Puede afirmarse que en las primeras décadas del siglo XVII no existió sólo una percepción de América en el arbitrismo peninsular, bastante negativa por lo general, ${ }^{10}$ sino que además tuvo lugar el desarrollo de un arbitrismo americano, o, para expresarlo con mayor propiedad, un arbitrismo centrado en cuestiones americanas. De hecho, fueron muchos los autores que en tiempos de dificultades del rey y del Reino, a ambos lados del Atlántico, utilizaron su ingenio para proponer soluciones en las que la realidad americana ocupaba el centro de su reflexión. ${ }^{11}$ Tal punto alcanzó la

9 Resulta sintomático de lo dicho hasta aquí que la obra de referencia de conjunto para el Consejo de Indias durante la época de los Austrias continúe siendo un trabajo excepcional publicado en la primera mitad del siglo XX. Me refiero a la de Ernst Schäfer, El Consejo Real y Supremo de Indias. Este hecho motivó que en el 2003 mereciera una reedición que incluyó un prólogo del profesor Antonio-Miguel Bernal, en el que se destaca su vigencia y utilidad y el hecho de que ningún estudio posterior haya conseguido superarla en su conjunto. Ver cita completa en nota 58.

10 Según Elliott, da la "impresión de que se produjo una reacción psicológica contraria a América, que, considerada antes como una fuente de grandezas para España, aparecía ahora como causa de su ruina". Elliott: "América y el problema", p. 9.

11 Para una aproximación tentativa, véase, entre otros, Evaristo Correa Calderón: Registro de arbitristas, economistas y reformadores españoles (1500-1936), Madrid, Fundación Universitaria Española, 1981, pp. 101-183. En los fondos de la Biblioteca Nacional de Madrid y la Biblioteca del Palacio Real existen muchos arbitrios referidos a asuntos americanos. Asimismo, se puede apreciar la frecuencia con la que el Consejo de Indias trabajaba sobre arbitrios presentados por particulares y por sus propios miembros en el Catálogo de consultas del Consejo de Indias, coordinado por Antonia Heredia Herrera. Hay que tener presente que muchas veces eran los propios consejeros quienes individualmente se reunían con los arbitristas para informarse sobre proyectos que en la mayoría de los casos no llegaban a ser considerados por ese organismo. Este procedimiento rara vez dejaba evidencia documental. Entre los estudios sobre el arbitrismo indiano pueden consultarse: Fred Bronner: "Peruvian 
proliferación de arbitrios en el ámbito indiano que, en Lima, durante la década de 1630, el virrey Chinchón aseguró que había encontrado "una cosecha muy importante de arbitristas". ${ }^{2}$

A pesar de este hecho, son muy pocos los trabajos que han tenido por objeto los arbitrios destinados a aquella parte del complejo hispano. Contamos con algunas aproximaciones, generalmente puntuales, que permiten formarse una idea muy genérica de este movimiento y facilitan un acercamiento a las características de la evolución económica, social, política y fiscal indiana durante el siglo XVII. Pero además de favorecer, con los debidos reparos, el conocimiento de la realidad americana, el estudio del arbitrismo está revestido de un gran interés por constituir un medio privilegiado para acceder a la esfera de las percepciones sobre los Virreinatos americanos y para evidenciar la circulación intelectual a escala trasatlántica. Así, su conocimiento podría ayudarnos a profundizar en aspectos esenciales como la imagen que se tenía de las Indias, tanto en España como en América, las ideas que se manejaban acerca de la naturaleza de sus dificultades - y por tanto de sus soluciones-, o las expectativas que estos territorios despertaban. En este sentido, al abordar constantemente el problema del mal gobierno, estos escritos resultan muchas veces una fuente de gran interés para el análisis concreto de la cultura y la práctica política por contener visiones coetáneas completas acerca de cómo era y, sobre todo, de cómo debería ser la administración de la Monarquía. Como un valor añadido de la utilidad de los arbitrios en el tema de las percepciones, hay que tener presente el hecho de que no eran únicamente un producto del pensamiento de los sectores más encumbrados de la sociedad, sino que también revelan discursos de grupos sociales más extensos y, en consecuencia, menos prominentes. ${ }^{13}$

Arbitristas under Viceroy Chinchón, 1629-1639", Studies in Hispanic History and Literature, XXVI, 1977, pp. 34-78 y "Tramitación legislativa bajo Olivares. La redacción de los arbitrios de 1631”, Revista de Indias, XLI, núm. 165-166, Madrid, 1981, pp. 411-441; Luis Miguel Glave: De Rosa y espinas. Economía, sociedad y mentalidades andinas, siglo XVII, Lima, Instituto de Estudios PeruanosBanco Central de Reserva del Perú, 1998; María Luisa Martínez de Salinas Alonso: "Contribución al estudio sobre los arbitristas. Nuevos arbitrios para las Indias a principios del siglo XVII". Revista de Indias, L, núm. 188, Madrid, 1990, pp. 161-170 y Javier Falcón Ramírez: Clases, estamentos y razas. España e Indias a través del pensamiento arbitrista del marqués de Varinas, Madrid, Consejo Superior de Investigaciones Científicas, 1988.

12 Bronner: "Peruvian Arbitristas", p. 36.

13 Como recordara Jean Vilar, "los hombres del siglo XVII no habían atacado tanto la incompetencia técnica de los arbitristas como la injerencia de esos hombres de poca monta en los problemas de alto bordo del Reino". Jean Vilar: Literatura y economía. La figura satírica del arbitrista en el Siglo de Oro, Madrid, Revista de Occidente-CSIC, 1973, p. 53. 
Por último, y como se deriva de lo dicho anteriormente, parece oportuno resaltar que el fenómeno del arbitrismo no posee sólo un interés erudito, sino que debe ser considerado como un elemento importante para poder llegar a establecer una relación más intensa entre la reflexión y la práctica política y, especialmente, para enriquecer nuestra comprensión de la elaboración de la política colonial en la corte de Madrid.

En estas líneas propongo una aproximación a un tema y a un autor particular de los muchos que vieron a América como un objeto de reflexión y como una realidad necesitada de reformas. Me ocuparé, específicamente, del arbitrismo sobre la administración indiana en los escritos de don Manuel Gaytán de Torres. Para ello me centraré en su obra más importante, las Reglas para el govierno destos Reynos y de los de las Indias, que dedicó al conde-duque de Olivares en $1625 .{ }^{14}$ Mi intención consiste, en primer lugar, en trazar un breve esbozo biográfico de Gaytán y en analizar las características de su obra. En segundo término, en realizar un estudio de la percepción de este autor acerca de la situación de la administración y de la organización institucional indiana de su tiempo - tanto en los Virreinatos como en la Corte de Madrid—, de las ideas que, según él, debían informar el ejercicio de los oficios y de los remedios que propuso para revertir la compleja situación que atravesaba el mundo hispánico en las primeras décadas del siglo XVII. En este sentido, la obra de Gaytán debe ser contemplada como una manifestación del intenso movimiento reformista que se impuso en la Corte de Madrid desde finales del reinado de Felipe III y se institucionalizó durante los primeros años del valimiento de Olivares, en el que tuvo una presencia notable la doctrina del neoestoicismo.

\section{Esbozo biográfico de don Manuel Gaytán de Torres}

No son muchos los datos que poseemos acerca de la vida de Gaytán de Torres, pero los pocos con los que contamos permiten contextualizar su obra, hacerse una idea de sus experiencias y comprender su empeño por introducir modificaciones en diversos aspectos de la realidad india-

14 Reglas para el govierno destos Reynos y de los de las Indias, con aumento en su población y en la Real hazienda, y armas de la mar [en adelante Reglas], s/d, 1625. Biblioteca Nacional de España, Madrid, 3/3532. 
na. ${ }^{15}$ Nuestro personaje nació en Jerez durante el último cuarto del XVI y era hijo legítimo de don Juan de Torres Gaytán y de doña Isabel Dávila. Casado con su prima hermana, doña Constanza Gaytán de Torres, tuvieron cuatro hijos. Los dos varones, don Juan Gaytán de Torres, caballero de la orden de Calatrava, y don Pedro Gaytán de Torres y Dávila, murieron sin descendencia. En cambio, sus dos hijas, doña Isabel y doña María, casadas respectivamente con don Agustín Adorno, caballero de Calatrava, y con don Antonio Moreno Estupiñán, caballero de Santiago, dieron continuidad a un largo e influyente linaje jerezano. Pocas son las certezas acerca de la vida de Manuel hasta el año 1619. En esta fecha se encontraba en la Corte de Madrid procurando interesar a los consejeros de Indias en un proyecto destinado a la instalación de ingenios y fundiciones de cobre en la Península, y gestionando una inspección a las recientemente descubiertas minas de Cocorote, en la provincia de Venezuela. ${ }^{16}$ En 1620 se le encargó la visita a dichas minas con la doble finalidad de comprobar la calidad del metal de los yacimientos y su productividad potencial y de estudiar el entorno con el fin de evaluar si éste era propicio para el asentamiento de una infraestructura de explotación y beneficio. ${ }^{17}$ La comisión tuvo una ejecución bastante rápida, puesto que en junio de 1621 Gaytán ya había redactado y dado a la imprenta una relación sobre las minas de Cocorote. Tras su regreso a Madrid, que debe situarse a finales del mismo año, don Manuel fue enviado a Sevilla para que, con asistencia del factor de la Casa de la Contratación, hiciera algunos experimentos con las mues-

15 La mayoría de los datos biográficos que poseemos corresponden a una información que, en el siglo XVIII, Joseph Manuel de Ayala obtuvo de un descendiente de Gaytán, don Francisco Ponce de León y Torres. Ayala se había interesado por las Reglas de Gaytán, por lo que encargó una copia que actualmente se encuentra en el Palacio Real de Madrid bajo el título Discursos que disponen medios para la restauración de España con mayor Cantidad de Renta en la real hacienda, y menos Gabelas en estos Reinos, y aumento de su Población, y en las fuerzas de la Mar [en adelante Discursos], s/d., Biblioteca del Palacio Real, Madrid, Ms. 1452. Entre las Reglas y los Discursos existen algunas variantes. Además de la mencionada semblanza biográfica, estos ejemplares tienen introducciones distintas y algunos pasajes diferentes.

16 Franco Urbani: "Las minas de cobre de Aroa a la luz de la relación de Manuel Gaytán de Torres, 1621”, Boletín Geológico y Minero, 103, núm. 2, Madrid, 1992, p. 159. Archivo General de Indias (en adelante AGI), México, 2, N. 258. Consulta del Consejo sobre las informaciones que don M. Gaytán de Torres ha dado de las minas de las provincias de Santa Marta y Venezuela, Madrid, 16 de septiembre de 1622. Las minas de cobre de Cocorote o Aroa fueron descubiertas en 1612 por don Alonso Sánchez de Oviedo. Hacia mediados de esta década el Consejo de Indias se interesó por las minas y la Casa de la Contratación realizó unos estudios con muestras de metal y piedra enviadas por el gobernador de Barquisimeto García Girón. Desconocemos de dónde procedía la experiencia de Gaytán en la minería cuprífera y su interés por los yacimientos de Cocorote.

17 Urbani: "Las minas de cobre", p. 159. 
tras de metal que había traído de Venezuela. Más tarde, el Consejo encargó el seguimiento del asunto de las citadas minas al consejero Rodrigo de Aguiar y Acuña, que debía tratar con Gaytán cada uno de los puntos del informe y evaluar sus conveniencias y dificultades. Si bien don Manuel fue reputado como una persona "bien entendida, de buena intención e inteligencia", como el negocio revestía gran importancia, requería pericia técnica y suponía un gasto muy significativo para la Real Hacienda, el Consejo sugirió adoptar una postura cautelosa y solicitar la intervención del gobernador y de algunas personas principales de la gobernación de Venezuela para que volvieran a considerar el proyecto y ofrecieran su parecer por escrito. En última instancia, la consulta planteaba que, una vez que el asunto hubiera sido considerado cautelosamente con la concurrencia de toda esa gente y se decidiera ponerlo en ejecución, Gaytán podría ser enviado para acometerlo. ${ }^{18}$ Sin embargo, ni su plan fue puesto en práctica, ni sus servicios volvieron a ser solicitados para dicho asunto.

A pesar de esto, don Manuel no regresó inmediatamente a Jerez sino que permaneció en Madrid, al menos hasta 1623. Allí desempeñó el papel de pretendiente y continuó intentando que se adoptara alguna determinación acerca de su proyecto. Gaytán aspiraba a ser recompensado por los servicios que había prestado y resarcido por los elevados gastos que tuvo que afrontar en el viaje a Venezuela. Hay que tener presente que no había recibido ninguna ayuda por parte de la Real Hacienda y que para poder pagar el viaje de regreso desde La Habana debió endeudarse en 200 pesos que no había podido devolver. En virtud de este hecho, el 13 de diciembre de 1622, Felipe IV le hizo merced de 200 pesos en penas de cámara del Consejo de Indias. ${ }^{19}$ Asimismo, obtuvo con cierta dilación un hábito de Calatrava para su hijo. Posteriormente, en fecha que no podemos precisar, fue considerado para la gobernación de Venezuela, aunque no se le incluyó en la terna de candidatos que solía presentarse al rey. ${ }^{20}$

Acabado el periplo que lo llevó a Venezuela, y satisfechas algunas de sus aspiraciones en la Corte, Gaytán regresó definitivamente a Jerez. En 1624 estuvo presente en el reconocimiento del terreno y en las mediciones, realizadas por dos ingenieros enviados desde Madrid, que tenían como

18 AGI, México, 2, N. 258. Ibidem.

19 AGI, Indiferente, 754. Consulta del Consejo de Indias sobre una petición de merced de Manuel Gaytán de Torres, Madrid, 12 de diciembre de 1622. Torres, s/d.

20 AGI, Indiferente, 1516, n. ${ }^{\circ}$ 266. Extracto de la relación de méritos de M. Gaytán de 
objetivo la construcción de un canal para comunicar los ríos Guadalquivir y Guadalete. Un año más tarde logró imprimir la obra que nos ocupa. A partir de aquí ya nada más sabemos de él, a excepción de que otorgó testamento el 17 de noviembre de 1633 y que murió el 28 de noviembre del mismo año. ${ }^{21}$

\section{Rasgos característicos del arbitrismo de Gaytán de Torres}

Al parecer, la inclinación arbitrista de Gaytán no fue un hecho puntual y circunscrito a su experiencia indiana, sino una inquietud que mantuvo, al menos, entre 1620 y 1625, cuando redactó numerosos arbitrios, algunos de ellos muy originales, entre los que destacan la Relacion $i$ vista de ojos de las minas de cobre de Cocorote en Venezuela ${ }^{22}$ y las Reglas para el govierno destos Reynos de los de las Indias, con aumento de su población y en la Real hacienda, y armas de la mar. El primero de ellos es un curioso proyecto de ocupación y desarrollo regional de la provincia de Venezuela, concebido en torno a las minas de Cocorote. Este escrito fue un producto directo de la estancia de Gaytán en América y apareció impreso en 1621, probablemente en Madrid.

En cambio, sus Reglas tienen un carácter y un origen más heterogéneo. Los seis escritos que aquí se reúnen poseen una amplitud temática y geográfica muy marcada. De hecho, en ellos es posible encontrar proposiciones acerca de los preceptos que debían regir los nombramientos de cargos de justicia, gobierno, milicia y las asignaciones de beneficios eclesiásticos; de la reforma del gobierno económico y político de las Indias; del modo de defender el estrecho de Gibraltar y establecer un sistema naval general para la Monarquía; de las ventajas del establecimiento de un sistema de riego en Murcia, Lorca y Cartagena; del desempeño de la Real Hacienda y del aumento de la población del Reino.

Asimismo, y a pesar de esta presentación de conjunto y de constituir, si no una obra completamente estructurada, al menos un escrito en el que

21 Discursos, fs. 2 y 3.

22 Relación y vista de oios que Don Manuel Gaytan de Torres Veintiquatro de la ciudad de Xerez, haze a su Magestad en el Real Consejo de las Indias, por comission que para ello tuvo de las Minas de cobre que hay en las Serranias de Cocorote, provincia de Venezuela. Año 1621. Hasta donde sabemos, el único ejemplar que se conserva se encuentra en la British Library, donde fue localizado por Urbani. Este autor reprodujo la Relación en el citado artículo, pp. 166-185. Existe una edición facsimilar, del año 1968, de Antonio Moreno Garrido. 
buena parte de sus proyectos están relacionados entre sí, parece bastante probable que algunos de los arbitrios hayan sido dados a publicidad o circulado antes de pasar a integrar las Reglas. Hay varias circunstancias que así lo sugieren. Este sería el caso, al menos, del segundo y más voluminoso de sus arbitrios - Que se de diferente modo al gobierno de las Indias, que se van perdiendo muy a prisa con el que hoy tienen-y de una parte del quinto - Que se trate de desempeñar la Real Hacienda. Sobre el primero de ellos, Antonio Nicolás refiere que Lorenzo Cocco Umbro, secretario del nuncio apostólico Lorenzo Campeggi y autor al que solía recurrir, había tenido oportunidad de consultarlo como obra independiente. ${ }^{23}$ Del segundo, en cambio, hemos encontrado en la Biblioteca Nacional de España un documento impreso, titulado Exposición a S. M. en contra de la subida del marco de plata propuesto por el Capitán Tomás de Cardona, que recoge algunos de sus postulados. Las Reglas se completan con otros cuatro arbitrios que abordan los temas referidos más arriba. Sería bastante probable que alguno más de estos escritos haya podido circular de manera autónoma, ya fuera de forma manuscrita o impresa, pero no tenemos ninguna evidencia documental al respecto. Tampoco de que Gaytán haya escrito otros proyectos y, por tanto, de que su obra arbitrista se haya extendido más allá de 1625 .

Hemos señalado ya que el movimiento arbitrista se definía tanto por sus prácticas como por sus discursos específicos. En este último aspecto, la obra de Gaytán debe inscribirse de lleno en el género, al presentar buena parte de sus rasgos característicos: está impregnada de sus peculiares formas de expresión y exposición, reproduce su estructura y su modo de argumentación y retoma sus objetivos, sus explicaciones y sus supuestos, como son una determinada concepción del complejo sociopolítico o una interpretación de la evolución de la Monarquía Hispánica. ${ }^{24}$

El lenguaje del texto resulta muy expresivo, ya que no sólo hace uso y abuso de un elenco muy característico de términos, sino que también

23 Nicolás Antonio: Biblioteca Hispana nueva: o de los escritores españoles que brillaron desde Augusto hasta el año de Cristo de MD hasta el de MDCLXXXIV, vol. II, Madrid, Fundación Universitaria Española, 1999, p. 93. También aparece de esta misma forma en la citada obra de Correa Calderón.

24 Para una caracterización muy clara de la estructura, la composición y el lenguaje arbitrista a través de la sátira literaria, véase Vilar: Literatura y economía, pp. 185-220. Sin embargo, como bien ha puntualizado Dubet, no hay que soslayar el hecho de que las peculiaridades del discurso arbitrista también aparezcan en otro tipo de documentos generados por las Cortes de Castilla, los Consejos o los Ayuntamientos. Dubet: "Los arbitristas", p. 5. 
incorpora frases hechas y giros idiomáticos presentes en el repertorio semántico arbitrista. Voces como restauración, reforma, conservación, utilidad, brevedad o declinación, y expresiones como "medios infalibles, fáciles, justos y experimentados", "mayor beneficio" u "obra milagrosa o total reparación de esta monarquía" jalonan asiduamente los escritos de Gaytán, denotando filiaciones discursivas - y también analíticas - con escritos como los de Sancho de Moncada o Martín González de Cellorigo.

Otro rasgo singular es el tono de su obra, que tiende a estar cargado de solemnidad y autoritarismo, "donde parece que ya el arbitrista disfruta expresándose como si fuera legislador", como diría Vilar. Asimismo, en este terreno existen otros dos aspectos que llaman particularmente la atención.

En primer término, el estilo llano y directo, que por momentos adopta el carácter de advertencia, que aplica para dirigirse a Olivares con la evidente intención de remarcar la compleja situación y la necesidad de introducir cambios según sus propias propuestas. Así, por su tono, la lectura de las Reglas tiende a hacer olvidar la dignidad del destinatario, llegando incluso a adoptar el carácter de consejo personal.

En segundo lugar, no deja de ser curioso el modo sentencioso que tiene de presentar con una certeza absoluta sus conclusiones, algunas de las cuales son, cuando menos, opinables o controvertidas. En esta misma tesitura, Gaytán tampoco se abstiene de resaltar varias veces la simplicidad de los medios que propone. ${ }^{25}$ De hecho, dejándose tentar por dos de los pecados más frecuentes del arbitrismo, la simplificación y el reduccionismo, presenta a sus escritos como el medio definitivo para superar la falta de recursos y no sólo como a un remedio coyuntural encaminado a engrosar momentáneamente las arcas reales. Incluso, evocando las duras críticas que Quevedo dedica a los arbitristas en La fortuna con seso y la hora de todos, promete una "mayor cantidad de renta en la Real Hacienda y menos gabelas en estos reinos". Ésta es una frase que introduce constantemente para atraer la atención de un gobierno necesitado, aunque cuidándose de salvaguardar los intereses del Reino.

En cuanto a la forma de exposición y argumentación, Gaytán tiende a utilizar el modo breve y compendioso propio de este tipo de escritos. Sin embargo, resulta forzoso precisar que su proyecto sobre las minas de Cocorote está presentado siguiendo un ritmo algo más pausado, fundamen-

25 Ibidem, p. 2; Vilar: Literatura y economía, p. 194. 
tado y minucioso. Por lo general, el desarrollo de las problemáticas en sus arbitrios suele hacerse según un esquema preciso. Tras exponer una descripción de la cuestión, se identifican las causas, que pueden ser tanto de carácter específico como genérico, material o moral, y se propone una o varias soluciones con cuotas de realismo muy variable. Por lo general sus escritos adolecen de una argumentación reiterativa, que recalca, una vez tras otra, asuntos como las dificultades que estaba atravesando la Monarquía o los beneficios de sus escritos para desempeñar la Hacienda Real sin introducir nuevas contribuciones.

Para constatar lo hasta ahora dicho, nada mejor que dejar hablar al propio autor a través de la dedicatoria de sus Reglas al conde-duque,

El alma, señor Excelentísimo, deste sujeto es representar las causas y principios de los daños que esta monarquía está padeciendo asi de mar como de tierra, señalando prácticamente medios certísimos para su reparo, juzgo con evidencia clara, que si V. Ex. les da audiencia que ha de mandar se ejecuten puntualísimamente y ha de gozar España por mano de VE el mayor beneficio que puede esperar como es su total desempeño sin cargo de imposiciones, pechos y gabelas. ${ }^{26}$

Llegamos entonces al objetivo principal de sus arbitrios, el mismo que constituye el denominador común de la inmensa mayoría de los escritos del género. Como afirma rotundamente Gaytán, la finalidad primordial a la que "miran estos discursos es a [...] desempeñar a su Majestad y ponerle descansado, rico y sobrado de Hacienda". ${ }^{27}$ Pero su consecución dependía, a su vez, del cumplimiento de otros objetivos parciales; este sería el caso de la reforma del gobierno indiano, sin lo cual no cabía ninguna posibilidad de alcanzar el desempeño de la Real Hacienda y aliviar las cargas del Reino.

Ahora bien, si resulta muy clara la identificación de sus objetivos esenciales, no es tarea sencilla encasillar sus escritos dentro de una de las vertientes del género. Su difícil catalogación es consecuencia de varios aspectos presentes en su obra: la relevancia, radicalidad y heterogeneidad de sus aspiraciones y la extensión del marco geográfico que aborda en sus propuestas. Así, sus proyectos no se circunscriben, como los de la mayor parte de los arbitristas, estrictamente al terreno económico, sino que abordan temas como la organización y los principios que debían regir la administración secular y eclesiástica, los asuntos navales, la política defensiva o el aumento demográfico. Asimismo, tienen una amplitud geográfica excep-

26 Reglas, p. 2. El destacado es del autor.

27 Ibidem, p. 67. 
cional al no ceñirse a un territorio específico del Imperio, por lo que su programa comprende un conjunto de reformas que de manera coordinada se debía extender a los territorios americanos y a Castilla. En este sentido, Gaytán concibe la Monarquía Hispánica como una unidad cuya restauración dependía, en buena medida, de lo que ocurriera en sus territorios trasatlánticos. En definitiva, su obra representa la concreción de una percepción, muy extendida en la época y paulatinamente recuperada por la historiografía actual, de la Monarquía entendida como un espacio común integrado y dinámico, en el que los sucesos y las coyunturas experimentadas por cada una de sus partes repercutían en el conjunto.

En términos generales, en su pensamiento tiende a primar un horizonte naturalista, tanto para el análisis como para la proposición de soluciones a la difícil situación de la Monarquía. Sin embargo, no elude validar el esquema providencialista moralidad-fortuna que preside buena parte del pensamiento hispánico de la época. Al igual que el común denominador de los arbitristas, su obra está impregnada de una decidida intención interventora y de un afán dispositivo y ordenador de la realidad, aunque con unos márgenes de maniobra bastante precisos. En el conjunto de sus proyectos se identifican tanto tendencias regeneracionistas como netamente reformistas. Así, por ejemplo, si bien en muchos aspectos propone la restauración de elementos pretéritos, como podría ser el restablecimiento de la autoridad real, de un ideal de administración desvirtuado o del sentido original de las órdenes militares, en otros se muestra como un innovador que propulsa la adopción de medidas absolutamente novedosas. De todos modos, no se debe perder de vista el hecho de que el pasado tiene un papel muy importante en el pensamiento de Gaytán, tal como ocurría con muchos de sus contemporáneos, y que las innovaciones debían estar en sintonía con un conjunto de supuestos tradicionalmente aceptados, que estaban fuera de toda discusión. En este aspecto, su proyecto recuerda al del valido, a quien "importaba tanto la revitalización de los valores tradicionales como la renovación o el cambio", tensión que se plasmó especialmente entre el carácter conservador de su política exterior y el tono innovador de la política interna. ${ }^{28}$

Finalmente, otro aspecto esencial es el del bagaje intelectual y de las fuentes que contribuyeron a perfilar las características de la crítica y las

28 John Elliott: El conde-duque de Olivares. El político en una época de decadencia. Madrid, Crítica, 2004, p. 741. 
propuestas de nuestro autor. Al igual que la gran mayoría de los individuos que cultivaron el género del arbitrismo, Gaytán no había realizado estudios formales. Su principal fuente de información fue su experiencia indiana, ya que era un sujeto inclinado a la observación de los problemas de su tiempo y se interesaba por el estudio de cuestiones prácticas capaces de modificar la realidad. De ahí que sus escritos sean muy parcos en referencias y citas; únicamente reconoce haberse inspirado en la Política para corregidores y señores de vasallos [1597] de Jerónimo Castillo de Bobadilla y en el Tratado de republica y policia christiana para reyes y principes [1615] de fray Juan de Santa María, obra a la que Gaytán se refiere como Doctrina de Príncipes. Pero si aquel es citado tan sólo en una oportunidad para apoyar una proposición muy concreta, éste, como veremos, ocupa un lugar relevante en su interpretación de la crisis y en su proyecto.

Más allá de este silencio bibliográfico, nada extraordinario por cierto en esta época, los arbitrios de Gaytán denotan, al menos, tres circunstancias destacables relacionadas entre sí. En primer lugar, es evidente que tenía un conocimiento apreciable de los arbitristas de su tiempo, hasta el punto de mantener consonancias evidentes con sus críticas y con varios de sus planteamientos básicos. En segundo término, Gaytán se revela como un autor muy compenetrado con las directrices reformistas del gobierno de Olivares, compartiendo cuestiones esenciales como la necesidad de rectificar la política de concesión de mercedes, el resurgimiento de la autoridad real, la lectura de los problemas y, especialmente, ciertas ideas acerca del papel de la administración y de los principios que debían informarla. Aquí entramos directamente en el tercer aspecto, el de la presencia de una inspiración neoestoica en Gaytán.

Como muchos otros autores y políticos de su generación, su pensamiento está influido por esta doctrina que experimentó un importante desarrollo a partir de las últimas décadas del siglo XVI, como parte del esfuerzo realizado en España por armonizar los preceptos religiosos con las exigencias de la cada vez más compleja y autónoma política moderna. La obra de Justo Lipsio, indudablemente el autor más destacado del neoestoicismo europeo, tuvo un gran atractivo para los españoles por ser un intento de reencauzar la relación entre política y ética que Maquiavelo había cuestionado, y por ofrecer una orientación procedente de la antigüedad clásica para hacer frente a la crisis que experimentaban. Pero también esta corriente filosófica ocupó un lugar esencial en la teoría política del Estado moderno, especialmente en lo que respecta a la exaltación del poder del 
monarca, al establecimiento de una administración y un ejército eficaz y disciplinado y al control social. En este sentido, el neoestoicismo puede entenderse como una "doctrina que aspiraba a la educación política y moral de los burócratas y hombres públicos en general", enfatizando el papel esencial de la observancia de virtudes tradicionales y estoicas en el desenvolvimiento del cuerpo político y en su regeneración. ${ }^{29}$

En el caso de Gaytán es importante reparar que la recepción de algunas de las ideas, y especialmente del espíritu neoestoico, no parece haber procedido directamente del estudio o la lectura de Lipsio o de otro de los autores de su época. Presumiblemente se haya debido, más que a cualquier otra cosa, al influjo del ambiente intelectual de su tiempo, circunstancia que contribuye a explicar también el recurso a un autor como fray Santa María, cuya obra recurre frecuentemente a Séneca y comparte elementos con el neoestoicismo.

En este punto hay que advertir un aspecto fundamental de la obra de Gaytán que permite entrever la faceta instrumental del conocimiento del arbitrismo y de la compenetración con el reformismo del régimen de Olivares, e insertar el acto de elevar arbitrios a las autoridades de un modo funcional en la cultura política de la época. Si bien los trabajos de Gaytán destilan una sincera voluntad reformista dictada por sentimientos de lealtad al monarca, no se debe soslayar el hecho de que, probablemente, también fueran concebidos como un instrumento potencial de promoción dentro de la administración. De hecho, parecería que nuestro autor intentó hacer usufructo de una coyuntura cortesana especialmente sensible al arbitrismo, proyectándose no sólo como un individuo compenetrado con las urgencias del momento, sino también como poseedor de un saber teórico - en este caso el domino de la obra de otros arbitristas y de un lenguaje determinado- y de una experiencia práctica — su viaje a América - que lo facultaban para formar parte de los cuadros administrativos de la Monarquía. Es decir que, en el contexto de una administración relativamente abierta a las

29 Salvador Cárdenas Gutiérrez: "La lucha contra la corrupción en la Nueva España según la visión de los neoestoicos", Historia Mexicana. LV, núm. 3, México, 2006, p. 724. Para una visión general del neoestoicismo puede verse la obra de Gerhard Oestreich: Neoestoicism and the Early Modern State, Cambridge, Cambridge University Press, 1982. Para su influencia en el contexto americano, véase, además de la citada obra de Cárdenas, Peer Schmidt: "Neoestoicismo y disciplinamiento social en Iberoamérica colonial (siglo XVII)", en Karl Kohut y Sonia Rose (eds.): Pensamiento europeo y cultura colonial, Frankfurt/Madrid, Vervuert/Iberoamericana, 1997, pp. 181-204; y Pilar Ponce Leiva: "Séneca en los Andes. Neoestoicismo y crítica social en Quito a fines del siglo XVII", Histórica, XXI, núm. 2, Lima, 2007, pp. 43-68. 
iniciativas de los súbditos, los arbitrios habrían sido la forma elegida por Gaytán para insertarse como miembro de una elite con la que tenía muchos elementos en común. Esta finalidad más concreta e individual, que no invalida una legítima vocación reformista, parece haber sido el elemento dinamizador de sus escritos para actuar en el marco de una cultura política determinada, ya que, como hemos visto, tras el fracaso de sus gestiones Gaytán no habría vuelto a presentar ningún otro arbitrio.

\section{Que se de diferente modo al gobierno de las Indias. Reformismo de la administración indiana}

Uno de los aspectos más sobresalientes de los trabajos arbitristas de Gaytán lo representan sus ideas y sus proyectos acerca de la administración indiana, que no sólo ocupan la parte principal de sus Reglas, sino que también constituyen uno de los ejes de su argumentación. Ahora bien, llegados a este punto cabe interrogarse respecto del sentido y la racionalidad de esta circunstancia y de la trascendencia que posee en el conjunto de las Reglas.

A diferencia del desencanto que, por diversos motivos, en ciertos sectores de la sociedad castellana estaba comenzando a despertar la posesión de los reinos americanos, Gaytán estaba plenamente convencido de que las Indias seguían siendo uno de los baluartes de la Monarquía, sin el cual no cabía posibilidad alguna de revertir la situación de la Real Hacienda. Para él, en caso de seguir descendiendo las remesas americanas del Rey, se habrían

de llevar tras de si lo que resta de esta Monarquía por que si le falta el dinero que cada
año viene porque no tiene otra sustancia, renta ni hacienda sino la que viene de las
Indias y si no se mira por ellas cierta será su ruina y estos reinos estar sin sustancia
para poder socorrer a su Majestad. ${ }^{30}$

El veredicto de Gaytán acerca de la administración indiana no podía ser más contundente, ya que su lectura parte de la progresiva disminución de la capacidad del poder central para controlar los Virreinatos americanos que ya se evidenciaba en su época. Coincidiendo con la avalancha de críticas que recibía el Consejo sobre el gobierno de esos territorios ultramarinos, sus escritos están plagados de referencias negativas no sólo a la orga-

30 Reglas, pp. 65-66. 
nización del entramado institucional, sino también al ideal que primaba en buena parte de los individuos que ocupaban puestos administrativos y a la forma en que eran proveídos los oficios. Para él, imperaba el mal gobierno en virtud de "los malos ministros que Su Majestad tiene en la administración de estas provincias y Hacienda Real". De un modo muy elocuente afirmaba que con "el poder y mano de sus oficios se llevan lo mejor de las Indias y son el fuego de ellas y han de dar ocasión a que todas se levanten". ${ }^{31}$ "Ministros, — aseguraba - que con malos medios adquirieron los oficios en que están" y que han dejado de velar por los intereses del monarca. Precisamente, una de sus ideas clave es la desvirtuación de la administración a raíz de la "codicia, la ambición y demás vicios y malas propiedades" de los servidores reales, circunstancia que los conducía a colocar sus fines particulares por delante de cualquier otro. Para Gaytán, estos individuos tenían una percepción de los oficios como una fuente de beneficio económico que, por encima de cualquier otra motivación, debía servir para recuperar lo que había invertido en las gestiones cortesanas. Este es el motivo del énfasis que pone en los malos modos con que eran nombrados los oficiales, especialmente durante el valimiento de Lerma. Podría hablarse, por tanto, de una crisis del ideal del real servicio o, al menos, de una percepción bastante distinta a la que se tenía en Madrid, y que se traducía en el debilitamiento de la potestad real. Todo esto había provocado que fuera la propia administración, que debía servir de mano ejecutora de las disposiciones concebidas en la Corte, la principal causa de la pérdida del Reino y de la reputación del monarca.

Un fenómeno que contribuía a agravar la situación del gobierno americano era el de las redes sociales establecidas por los consejeros de Indias que, partiendo de Madrid, tenían una incidencia nefasta en el ejercicio del patronazgo, en el gobierno y, específicamente, en el manejo de la Hacienda. Estos vínculos interpersonales habían dado pie, entre otras cosas, a la desvirtuación de la administración de las Indias y a la neutralización de los intentos de reformar o suprimir algunas instituciones. Según su entender, los consejeros habían hecho de los cargos americanos un ámbito de patrocinio excepcional para sus parientes y criados, siendo responsables de un "depravado estilo de gobierno [...] por favorecer a los deudos, amigos y bienhechores que tienen en las Indias". ${ }^{2}$ La consecuencia

31 Ibidem, pp. 23-24.

32 Ibidem, p. 29. 
más inmediata de esta práctica era el nombramiento de individuos que no estaban dotados moralmente ni capacitados para formar parte de la administración, que alteraban su orden y su finalidad e, incluso, impedían la sanción de los actos ilícitos.

La necesidad de alcanzar una solución para la administración tenía un carácter aún más urgente, si cabe, a raíz de la forma que tenía Gaytán de interpretar la relación entre el rey y el Reino y el papel del gobierno. Nuestro autor utiliza una concepción muy extendida en su época que entendía la Monarquía como un cuerpo y a su gobierno como la cabeza. Así como la cabeza conduce y ordena a los miembros, el gobierno debe orientar al cuerpo político. De ahí que presentara sus males como enfermedades y sus proyectos como remedios. Consecuentemente, resalta la primacía que se le debe conceder a los asuntos propios del gobierno, "por ser como es el [responsable del] bien o el mal de los Reynos y Repúblicas" y, por tanto, "todos los daños que suceden a una República se deben atribuir a los que la gobiernan por no prevenir con tiempo el remedio". ${ }^{33}$ De este hecho se deducía "la obligación que tiene el rey de elegir las personas más beneméritas en las dignidades y oficio del gobierno eclesiástico y secular de sus repúblicas que como cabezas y espejos de los demás deben ser hombres perfectos" ${ }^{34}$ Es decir que, según él, existía una relación entre las cualidades del gobierno y la suerte del conjunto de la sociedad, que obligaba a que, tanto la organización de la administración como los individuos que ejercían las funciones públicas fueran idóneos y se guiaran según los altos ideales que debían trasmitir al cuerpo político. Por este mismo motivo, Gaytán se mostraba muy optimista respecto a las posibilidades de la acción política, a la que concedía un papel esencial en la modificación de las realidades concretas. Esta gran responsabilidad asignada a la organización del gobierno, no del todo justificada, se hacía eco de una idea que también había sido aceptada a pie juntillas por el régimen de Olivares. Para el valido, como para muchos otros de sus colaboradores, la restauración del reino pasaba más por ser una cuestión de gestión política que de mecánica social. ${ }^{35}$

En líneas generales, las numerosas medidas que propone en el ámbito de la administración tienen como finalidad la consecución de dos objetivos íntimamente vinculados entre sí: establecer un modo más eficaz de ejercer el gobierno y reducir los gastos que debía afrontar la Real Hacienda

33 Ibidem, p. 66.

34 Ibidem, p. 7.

35 Elliott: El conde-duque de Olivares, p. 216. 
para mantener la estructura administrativa indiana. Para que esto fuera posible era necesario poner de pie lo que había sido puesto de cabeza, y sustituir completamente las ideas y los procesos que presidían el sistema de consulta de los oficios, disponiendo las cosas de manera tal que las plazas se concedieran a las personas más idóneas, que eran las que más se acercaban a un modelo muy concreto. Ésta es la base de su proyecto reformista y donde pueden apreciarse algunos elementos propios del neoestoicismo aplicado al campo de la administración.

A pesar de la variada gama de remedios propuestos por Gaytán, su regeneracionismo debe entenderse en clave moralizante. En esta línea, su pensamiento estaba fundamentado en la aceptación de una noción muy extendida, según la cual los príncipes se apoyaban en los súbditos y no en las instituciones. Como refiere José Luis Abellán, “a partir de aquí la política aparece construida sobre el acto volitivo, [de ahí] que el punto primario de reflexión es para todo político el hombre" ${ }^{36}$ En esta tesitura, uno de los argumentos más utilizados en este periodo para explicar la declinación de la Monarquía era la pérdida de las virtudes, circunstancia que muchos autores parangonaron con la crisis del Imperio Romano. Así, según Gaytán, "lo que principalmente se debe mirar en un ministro es el ajustamiento de su conciencia, que no hará advertidamente acción contra ella por cuanto tiene el mundo". Por lo tanto, para exaltar el poder real y para que los miembros de la administración pudieran ser cabezas y espejos del cuerpo político era fundamental que éstos estuvieran adornados de un conjunto de virtudes tradicionales y estoicas. Había, entonces, que atajar los vicios, como la codicia y la ambición que motivaban a los integrantes de la administración. Siguiendo esta idea afirma tajantemente que "cuando concurren dos [candidatos] uno de aventajada virtud y mediano gobierno y otro al contrario de superior gobierno y de inferior virtud, se ha de elegir el superior en esta". ${ }^{37}$ En este aspecto esencial remite a los consejos de fray Santa María, defensor del desarrollo y la enseñanza de una ciencia de gobernar, para quien la crisis de la Monarquía tenía un carácter moral y una de sus causas esenciales en los criterios de elección utilizados. Por esta razón recomendaba una escrupulosa selección de los servidores reales, teniendo especial cuidado de que además de poseer saberes acordes al cargo al que iban a ser destinados, fueran individuos piadosos; firmes, valien-

36 José Luis Abellán: Historia crítica del pensamiento español, t. 3, Madrid, Espasa Calpe, 1981, p. 106.

37 Reglas, pp. 11-12. 
tes y constantes en sus virtudes; más inclinados a la justicia y a la verdad que a congraciarse con el monarca; sobrios y prudentes. ${ }^{38}$ Implícitamente debían ser personas capaces de controlar los afectos y sus inclinaciones personales - entre ellas la codicia y la ambición- para servir a fines superiores a sus intereses particulares.

A su vez, resultaba prioritario que tuvieran auténtica conciencia de las repercusiones, las cargas y los riesgos de los oficios, y que estuvieran dispuestos a servirlos más por prestar un servicio al monarca que por cualquier otro motivo. Gaytán es muy elocuente al explayarse en esta idea. Según él,

\begin{abstract}
ha mostrado la experiencia en todos los siglos pasados que aquellos a quien pusieron a gobernar contra su voluntad gobernaron excelentísimamente porque fueron hombres ajustadísimos en su conciencia y como tales reconocían el riesgo que corre un alma en el gobierno y así se huían. Y quien pretende muy lejos está de reconocer este riesgo y carga que se hecha sobre sus hombros, mira sólo los resplandores del oro de la corona más no la carga y peso incomportable de quien se ciñe las sienes con ella [...] quien huye del oficio es bueno para él, no quien le busca, porque este da bien a entender con su pretensión que sólo quiere el oro de la corona y dejar para sus inferiores el peso de su resplandor.
\end{abstract}

Finalmente, haciéndose eco de una idea muy presente en su tiempo, Gaytán destaca la capacitación del individuo para el cargo. Pero atiéndase que no se refiere a la posesión de un talento particular, sino a la capacidad asentada en la experiencia y en el buen desempeño de funciones anejas a las que se le habrían de encomendar. En esta cuestión su opinión era que se debía preferir a los beneméritos, es decir, a aquellos individuos dignos de ser atendidos y estimados por las obras buenas que han hecho y por las cuales merecen la común aceptación y estimación pública. "El oficio y dignidades se han de dar al que es perito en aquel arte y con las partes" ${ }^{39}$ Asimismo, era preciso respetar un escalafón que debía llevar a los individuos de oficios de menor responsabilidad a otros de mayor, debiéndose evitar las hechuras que lo vulneraban. En esta cuestión también encontramos una asociación con el régimen del valido. La falta de cabezas, es decir, la escasez de personas cualificadas para ejercer los cargos públicos, era considerada por Olivares uno de los males de su tiempo, y lo achacaba, en buena medida, a la

38 Fray Juan de Santa María: Republica y policia christiana para reyes y principes y para los que en el govierno tienen sus vezes, Barcelona, Casa de Lorenzo Deu, 1619, fs. 36-55.

39 Reglas, p. 17. 
poca experiencia de los individuos causada por la falta de respeto a un sistema que permitiera acumularla progresivamente, partiendo de los niveles inferiores de la administración hacia los superiores. ${ }^{40}$

Curiosamente estas ideas no le impiden encomiar a los colegios mayores con sus estatutos de limpieza de sangre y su proyección en la administración de justicia, alejándose en este aspecto de las propuestas de Santa María.

Conocemos ya las cualidades que debían poseer quienes ejercieran los oficios, pero también era preciso establecer un modo de proveerlos que fuera capaz de satisfacer tan altas expectativas. Fuera por la dificultad de obtener informaciones veraces sobre los candidatos, por parte de los consejeros, o por la incidencia del favoritismo, lo cierto es que se había desvirtuado el sistema de proveimiento. Sobre todo se había introducido una práctica muy perjudicial según la cual el pretendiente procuraba obtener un cargo mediante prolongadas y costosas gestiones en la corte, intentando "hacer capaz su persona con servicios". ${ }^{41}$ De tal manera, la Corte se llenaba de pretensores que fomentaban vicios, dejaban de cumplir con sus obligaciones y consumían haciendas que luego intentaban recuperar en el ejercicio de los oficios. Por tanto, resultaba fundamental reformular el sistema, ya que los servicios no hacían capaces a los hombres para cualquier puesto, que la mayoría de los que más ahínco ponían por conseguir un cargo solían ser los que peor lo servían, y que los consejeros no podían conocer realmente el perfil moral de los individuos. Según Gaytán, en el ámbito cortesano estos pretendientes eran capaces de ocultar sus defectos tras una fachada de "autoridad y compostura, severidad, acciones y palabras compuestas que las más de las veces es todo fingido". En este argumento resuenan las duras críticas neoestoicas a la teatralidad cortesana, artificial e ilusoria, que desvirtuaba la apreciación de la realidad y conducía a la toma de decisiones poco pertinentes. ${ }^{42}$ Por eso recordaba que "los Reyes que han querido acertar han enviado los oficios a los que los han de ejercer y no los dan a los que los venían a buscar a sus cortes llenos de ambición y otros defectos que se hallan en los pretendientes". ${ }^{43}$

40 Consulta del conde-duque a Felipe IV en respuesta de ciertos papeles y memoriales tocantes al bien público y gobierno destos reinos, en John Elliott y José de la Peña (eds.): Memoriales y cartas del conde-duque de Olivares, II, Madrid, Alfaguara, 1981, p. 163.

41 Reglas, p. 20.

42 Cárdenas Gutiérrez: "La lucha contra la corrupción”, pp. 727-733.

43 Reglas, p. 7. 
El método que proponía apuntaba a centralizar el proceso en el monarca y consistía en la erradicación del sistema de consultas de los Consejos y en quitarles el patronazgo a los virreyes. En su reemplazo sugería conformar unos libros que debían contener las personas "que más lucen en virtud de prudencia y gobierno de sus casas y repúblicas" en cada una de las ciudades de los Reinos de la Monarquía. Dichos libros tenían que confeccionarse por individuos de crédito que, desde todos los rincones del Imperio, remitieran, de forma secreta, información de las personas más idóneas. ${ }^{44}$ Así, Gaytán propone como ejemplo una tabla de doble entrada en la que para cada nombre hay una serie de columnas en las que se debía consignar la edad, el entendimiento, la conciencia, la prudencia, la calidad, la formación, la experiencia en el gobierno civil o militar de cada uno de los candidatos. Compuestos por estos datos, los libros debían ordenarse de modo tal que permitieran la rápida consulta de los individuos adecuados para cada oficio. A estos inventarios recurriría el rey cada vez que fuera necesario cubrir una vacante. Quedaba, por tanto, excluida de este sistema la venta de oficios como principio de provisión de cargos, así como el otorgarlos en recompensa por servicios prestados. Estimaba Gaytán que este método resultaría muy eficaz para que se pudieran tomar decisiones con un conocimiento más preciso de los potenciales miembros de la administración y, de este modo, hacer lucir la virtud en los Reinos de la Monarquía. A partir de esta reforma sería posible elegir "personas capaces, consultadas sin pasión ni aflicción ni particular interés" y se neutralizarían las perniciosas consecuencias de proveer oficios en personas no capacitadas para el cargo para el que habían sido nombradas. En una crítica abierta al valimiento de Lerma, Gaytán llega a afirmar que el reinado de Felipe III se había caracterizado por dar "a letrados administraciones de guerra y despachos de flotas y a soldados gobiernos y a regidores oficios de milicia y a otros que no han visto la guerra compañías y tercios". Finalmente, otra de las virtudes de este sistema era el abandono de la Corte por parte de los pretendientes. Incluso, con bastante ingenuidad, llegaba a concebir este método como un medio de control social, ya que la promoción de personas de

44 Este recurso a la fama pública de los candidatos, filtrada por el criterio de personas de reputación, aparece en la obra de Santa María. Hay que tener presente que el énfasis hecho por este autor, y recogido por Gaytán, en las virtudes y capacidades de los individuos que se promovían a la administración y en el sistema de información, llevaba implícita la abolición del principio de nombramiento según el lugar de procedencia. Como es sabido, esta era una de las ideas fundamentales del Gran Memorial de Olivares, que procuraba por este medio reforzar la unión entre los diferentes Reinos de la Monarquía hispana. Elliott y Peña: Memoriales y cartas, I, pp. 49-100. 
vida ejemplar y virtuosa fomentaría la emulación en el conjunto de la sociedad. ${ }^{45}$

Las rentas, en cambio, debían reservarse para premiar casos muy particulares. Era preciso estrechar el caudal del río de la merced que tanto había corrido durante el reinado anterior. Las mercedes que significaran una carga para la Real Hacienda, se debían otorgar como contrapartida de servicios militares, pero sólo a los huérfanos y a las viudas de personas que hubieran muerto en acto de servicio y no en oficios de justicia, gobierno o pluma. Para estos casos, aseguraba, bastaba "por premio la grandeza que tuvieron durante el oficio". Esta propuesta guarda estrecha relación con las ideas de Olivares acerca de los destinatarios adecuados de las honras y las mercedes. Durante su valimiento, estos principios se intentaron poner en práctica, aunque finalmente no se respetaron. ${ }^{46}$

Sin embargo, al referirse a las prácticas políticas destinadas a asegurar la gobernabilidad de los territorios trasatlánticos, Gaytán se ve forzado a suavizar sus ideas. La experiencia indiana había revelado a nuestro autor la existencia de acusados descontentos entre los criollos beneméritos, a raíz de los agravios que habían padecido al ser relegados en la asignación de encomiendas. Para él, era preciso ejercer de una forma más equitativa la distribución de la gracia y poner en cumplimiento la legislación referente a la repartición de encomiendas. De esta manera se sosegarían las malas voluntades y se neutralizaría cualquier intento de levantamiento. Además, este proceder sería un medio adecuado para obtener mayor consenso de los grupos de poder local, lo que brindaría a la Real Hacienda un margen de maniobra mayor para poder apropiarse de una décima parte de las rentas de dichas asignaciones. ${ }^{47}$

En una órbita más extensa, el reformismo de nuestro autor tenía por objeto la alteración de la "máquina de los Consejos". Aquí, sus preocupaciones esenciales eran la simplificación, la reducción del gasto, la adaptación de la organización institucional y jurisdiccional a la evolución que habían tenido los territorios indianos y la aceleración del ritmo del gobierno. El complejo polisinodial, creado por los Austrias para gobernar una Monarquía compuesta y brindar una atención particularizada a ciertos asuntos, debía ser suprimido y quedar operativos tan sólo los dos más

45 Ibidem, p. 16.

46 Véase el "Memorial sobre las mercedes" de 1621. Elliott y Peña: Memoriales y cartas, I, pp. 9 y ss. y II, p. 72.

47 Ibidem, pp. 101-104. 
importantes: los Consejos de Estado y de Justicia. ${ }^{48}$ Con cierta exageración, Gaytán señalaba que una vez que se retirase de los Consejos la facultad de consultar mercedes y oficios, tan sólo les quedarían unos pocos asuntos más que tratar, a excepción de la impartición de justicia. ${ }^{49}$ Con estas modificaciones se establecería una centralización que aceleraría el ritmo del gobierno en el Consejo de Estado, único encargado de velar por el gobierno de los reinos particulares y por la conservación de la Monarquía en su conjunto. Además, se evitarían las prolongadas y costosas disputas entre los Consejos por problemas de jurisdicción. ${ }^{50}$

Por su parte, los asuntos de Indias pasarían a depender directamente de este Consejo que, para acortar las deliberaciones, se conformaría con un máximo de seis integrantes seleccionados con gran cuidado en función de la capacidad y la experiencia. Aseguraba Gaytán, y en esto coincidía con el punto de vista de Olivares, que no existían muchas personas en la Monarquía capaces de ocupar estos puestos, ya que además de ser sujetos de talento deberían haber "visto mucho y tratado con diferentes naciones y gobernado con aprobación de muchos oficios". ${ }^{51}$

Las funciones judiciales de los Consejos particulares experimentarían un camino semejante al de los asuntos de gobierno, trasladándose al Consejo de Justicia. Pero, con el fin de que siguiera existiendo cierta especialización en la actividad judicial, se establecerían salas de jueces letrados para que "conforme a derecho y ordenaciones de los reinos de que tienen dependencia conozcan y juzguen de los pleitos que vienen de los dichos reinos y no de otra cosa".

Finalmente, el manejo de la Hacienda, una vez suprimido el Consejo correspondiente, debía quedar a cargo de un contador mayor y de un escribano de rentas que, asistidos por personal subalterno, darían un despacho mucho más rápido a estas cuestiones. ${ }^{52}$

48 Ibidem, pp. 19 y ss.

49 En este sentido, hay que tener presente que si se analizan las temáticas de las consultas del Consejo de Indias durante la gestión del conde-duque de Olivares, se observa una clara supremacía numérica de las que tratan sobre mercedes y nombramientos. De todas formas, este Consejo mantenía un papel primordial en la elaboración de la política colonial. Ver: Antonia Heredia Herrera (dir.): Catálogos de Consultas del Consejo de Indias, t. IV, V, VI y VII, Sevilla, Diputación provincial, 1985-1990.

50 Este hecho revestía tal gravedad, que en el año 1626 se estableció una Junta Grande de Competencias que debía dirimir las disputas jurisdiccionales entre los Consejos. Véase: Luis María García-Badell Arias: "La Junta Grande de Competencias de Felipe IV: Rey, nobleza y Consejos en la Monarquía Católica”, Cuadernos de Historia del Derecho, vol. extraordinario, Madrid, 2004, pp. 105-136. 51 Reglas, pp. 21-22.

52 Ibidem. El Consejo de Hacienda fue reformado en dos oportunidades desde el inicio del reinado de Felipe IV. Elliott y Peña: Memoriales y cartas, I, pp. 119-131. 
Es posible apreciar que este plan, de muy difícil aplicación, guardaba gran sintonía con las aspiraciones de un gobierno que, con una intención centralizadora, procuró racionalizar la administración y volverla más dinámica. En la práctica, Olivares potenció la vía ejecutiva en los Consejos en un intento de hacer frente, de un modo eficaz, a los cada vez más numerosos focos de conflicto que surgían en diversos rincones de la Monarquía. Los sínodos debían no ser tan sólo una instancia de asesoramiento sino, por encima de todas las cosas, el primer eslabón de una cadena de mandos que además de transmitir las disposiciones, debía asegurar su cumplimiento. ${ }^{53}$

Previendo que su solución fuera considerada demasiado radical y se optara por la continuación del sistema de Consejos, tal y como había existido hasta ese momento, nuestro autor concibió un paliativo que tenía como destinatario concreto al de Indias. Como no podía ser de otra manera, éste era, según su visión, el principal responsable de que estuvieran asoladas. La razón no radicaba en otro asunto más que en la condición de los consejeros. Cuestionaba Gaytán que este organismo se encontrara compuesto, en su gran mayoría, por letrados que no tenían más formación que la académica, ni otra experiencia que la de los tribunales de justicia. Para él, esto no tenía sentido puesto que, aparte de poseer la jurisdicción suprema de las Indias, el Consejo estaba encargado de las materias de gobierno, hacienda, gracia y guerra. Si bien recordaba que para el tratamiento de esta materia se había establecido la Junta de Guerra de Indias, también puntualizaba que el cuerpo de consejeros letrados seguía ejerciendo su influencia en un asunto que por estos años había cobrado una importancia fundamental a raíz de las incursiones y de las conquistas holandesas en el Virreinato del Perú. Finalmente, concluía que dicha circunstancia había derivado en una situación en la que se alteró el orden natural de la administración, porque encargar a letrados todas esas materias era como "pedir al ciego que juzgue de colores"..$^{54}$

La ignorancia de los asuntos indianos por parte de los letrados es un tema recurrente en la crítica de Gaytán, que se sustenta en el gran hincapié que pone en señalar la originalidad de las realidades americanas y en su convencimiento del papel decisivo de la experiencia para el buen

53 Véase, por ejemplo, AGI, Indiferente, 615. Decreto Real al presidente de Indias encomiándole el cumplimiento de las órdenes que se envíen. Madrid, 14 de octubre de 1623.

54 Reglas, p. 67. 
gobierno. ${ }^{55}$ Su posición en el dilema entre ciencia y experiencia, abordado por varios autores contemporáneos, era muy cercana a la del valido, para quien tanto los militares como los letrados, que habrían de ser promocionados a la alta administración, tenían la obligación de conocer los distintos reinos de la monarquía para penetrar en sus modos particulares de gobierno. ${ }^{56}$

La solución que proponía para esta cuestión resultaba poco original: era preciso ordenar la administración de tal forma que cada uno de sus miembros "tratara de su facultad y profesión y de las cosas que ha visto y practicado, como es el letrado de pleitos, el soldado de guerra, el marinero de navegar" ${ }^{57}$ En este sentido, los ocho consejeros letrados, establecidos por las ordenanzas de 1571, debían ser reemplazados por sólo seis consejeros de capa y espada. Pero este cambio no era suficiente por sí mismo; tal y como se había propuesto en otras ocasiones, también era necesario que los nuevos consejeros de capa y espada tuvieran amplia experiencia indiana. ${ }^{58}$ Con bastante minuciosidad, Gaytán recomendaba que respondieran a la siguiente calificación: dos de ellos debían elegirse entre las personas más prudentes que hubieran gobernado y militado en las Indias; otros dos tendrían que ser hombres de mar y haber navegado a América y a las islas Filipinas; finalmente, sería conveniente que los dos restantes hubieran tenido experiencia en los juzgados de Sevilla y Cádiz. Dentro de este renova-

55 Sobre la ignorancia de los consejeros letrados, Gaytán dice maliciosamente que "como no han visto las Indias, mar ni navíos, mal sabrán de su gobierno y apresto, habiendo gastado toda su vida en Salamanca y en su Colegio y de él sacados para oidores del Consejo de Indias donde en todo el año no se ven doce pleitos y los que de ordinario hay consiste su determinación en cuatro ordenanzas que están en romance". En este asunto reproduce un tópico de las críticas de la nobleza al tipo de gobierno implementado por Felipe II, caracterizado por la proliferación de los letrados en las tareas de gobierno. Véase José María García Marín: "El dilema ciencia-experiencia en la selección del oficial público de la España de los Austrias”, en José García Marín: Teoría política y gobierno en la monarquía hispánica, Madrid, Centro de Estudios Políticos y Constitucionales, 1998, pp. 17-41 y Pere Molas Ribalta: Los gobernantes de la España moderna, Madrid, Pasado Vivo, 2008, pp. 125-126.

56 Elliott y Peña: Memoriales y cartas, t. II, p. 71.

57 Reglas, p. 70.

58 La necesidad de que los consejeros de Indias tuvieran experiencia americana se planteó en numerosas oportunidades. Una de ellas, probablemente la de mayor relevancia, tuvo lugar tras la visita que a esta institución realizó en 1568 Juan de Ovando, para quien las plazas de consejero debían ser provistas entre los oidores indianos. Ernst Schäfer: El Consejo Real y Supremo de las Indias [1935], vol. I, Madrid, Junta de Castilla y León - Marcial Pons, 2003, pp. 136-140. A pesar de estos proyectos, la situación no cambió. De hecho, durante la primera mitad del reinado de Felipe IV tan sólo cuatro consejeros tuvieron experiencia indiana: Juan de Solórzano Pereira, Juan de Carvajal y Sande, Bartolomé Morquecho y Juan de Palafox. Muchos otros tuvieron una experiencia indirecta de los asuntos americanos en la Casa de la Contratación o en la Audiencia de Grados de Sevilla. 
do esquema, el presidente también debía ser una persona de capa y espada que hubiera navegado y ejercido alguna gobernación en los Virreinatos americanos. De esta forma se contaría con consejeros versados en todas las materias tratadas en el Consejo y no habría necesidad de continuar con la Junta de Guerra. Respecto a la labor judicial de este sínodo, Gaytán no es muy claro en la proposición de un sistema alternativo, pero parece barajar la posibilidad de contar con asesores en esta materia, lo que no dejaba de presentar bastantes dificultades..$^{59}$

Por último, proponía radicar el Consejo de Indias en Sevilla para que asistiera directamente al despacho de las flotas y las armadas, a la vez que suprimir la Casa de la Contratación. ${ }^{60}$

Hasta aquí hemos descrito el proyecto de Gaytán para las instituciones metropolitanas que debían encargarse de los asuntos americanos. Ya en el terreno de la administración propiamente indiana, sugería distintas modificaciones en los oficios y en las jurisdicciones institucionales. Su idea fundamental era que aquellos territorios habían sido desatendidos por la administración central durante mucho tiempo, habiéndose producido un desfase entre la organización institucional allí establecida y las características que paulatinamente fueron adquiriendo las realidades americanas.

En este contexto, los problemas que considera más graves son los relativos a los oficiales reales y a las instituciones de la Real Hacienda, porque "no sólo interesa a S. M. los sueldos que da a las personas que en los tales oficios se ocupan, sino otros daños mayores que causan las personas a cuyo cargo están los oficios que conviene cercenar". En primer lugar, tocaba el turno de reformar los Tribunales de Cuentas. Si bien estos tribunales, establecidos en México, Lima y Santa Fe, habían sido creados con la finalidad de centralizar la revisión de cuentas, imprimir mayor velocidad en su finiquito y evitar los fraudes, no habían servido, según nuestro autor, más que para producir "daño y oscuridad" y para gravar aún más a la Real Hacienda. ${ }^{61}$ Tal como se encontraban, no servían "más que para acomodar deudos, amigos y bienhechores de los consejeros letrados". En consecuencia, Gaytán sugería su supresión y su reemplazo por un sistema de control, excesivamente simplificado, de residencias tomadas al momento de producirse un nombramiento. De este modo se simplificaría notablemente el pro-

59 Reglas, pp. 65-71.

60 Ibidem, p. 69.

61 Ibidem, pp. 76-79. Esta impresión parece confirmarse en las opiniones del visitador de la Audiencia de Lima, Juan Gutiérrez Flores. AGI, Lima, 276. 
ceso, se evitarían los retrasos en el fenecimiento de las cuentas y, sobre todo, se podrían ahorrar hasta veintiséis mil ducados anuales. ${ }^{62}$ Con esta propuesta Gaytán coincidía con una corriente de opinión que había propuesto al Consejo idéntica solución, aunque aseguraba que las contadurías no se habían "consumido" por la oposición de los consejeros, que no estaban dispuestos a suprimir cargos para los que ellos proponían los candidatos, ni a desacomodar a las personas que habían favorecido. Refería que éstos habían conseguido desbaratar este asunto - y muchos otros- opuesto a sus intereses, a pesar de haberlo tratado varias veces el presidente Carrillo con el rey. ${ }^{63}$

Continuando en el ámbito de la Hacienda, también sus propuestas alcanzaron a los oficiales reales de las cajas indianas. Incluyéndolos en ese clima de desvirtuación del servicio real ya descrito, Gaytán aseguraba que la mayoría de ellos no tenía ninguna intención de servir su oficio desinteresadamente, sino que sus únicas preocupaciones se limitaban a ganar dinero y a resarcirse de los gastos que habían tenido que afrontar para conseguirlo. Tanto era así que, mientras realizaban sus gestiones cortesanas, los pretendientes ponían todo su empeño en enterarse de las remuneraciones de los oficios y de las oportunidades de negocios y granjerías que ofrecían las distintas regiones de las Indias. Pero si difícil era encontrar oficiales reales que cumplieran con su función, no lo era menos llevar adelante cualquier causa contra ellos. A raíz del carácter indefinido de los nombramientos de estos oficiales y de poseer en muchos casos estrechos vínculos con los consejeros, muy pocos individuos se atrevían a denunciarlos ante las autoridades superiores. Asimismo, Gaytán refiere que las dificultades de hacer justicia se agudizaban por los frecuentes arreglos que tenían lugar entre oficiales reales y gobernadores, que reducían notablemente las posibilidades de que una investigación prosperara.

Su plan consistía en que los oficiales reales dejaran de ser designados por el Consejo de Indias y que su nombramiento pasara a depender de los Cabildos indianos. Debía mandarse a los Ayuntamientos que, junto con los gobernadores, se encargaran de administrar la hacienda, nombrando cada año dos regidores que detentarían los oficios de tesorero y contador sin percibir salario alguno. De esta manera el tesoro real se podría librar de un gasto aproximado de doscientos mil ducados y la hacienda estaría

63 Ibidem, pp. 76-79 y 108-112. 
manejada por gente versada en los usos y costumbres de cada lugar. ${ }^{64}$ Además, habría una mayor claridad en las cuentas, ya que todos los años se debían tomar y remitir los alcances a España y, en ocasión de la residencia del gobernador, se inspeccionarían las cuentas de todos los regidores que se hubieran desempeñado como oficiales reales durante todo el periodo. ${ }^{65}$

Si las propuestas de Gaytán de Torres respectivas a la Real Hacienda tienen un carácter radical, aunque cuanto menos ingenuo, sus ideas concernientes a la reforma de la administración de justicia en las Indias son puntuales y localizadas. En este aspecto, sus escritos se ciñen tan sólo a una reorganización de los tribunales superiores de justicia americanos. Más preocupado por aligerar a la sobrecargada Real Hacienda y maximizar los beneficios generados por los territorios trasatlánticos de la Monarquía Hispánica, su atención no se centra en las demás instancias judiciales indianas ni en el ejercicio de la justicia. Apoyándose en una serie de generalizaciones y en un conocimiento muy precario del conjunto de la América española — a excepción de las regiones que visitó-, propone que en todas las Indias no se mantuvieran más de tres Audiencias. A raíz de la notable disminución de población indígena y del reordenamiento de la población, fundamentalmente en la región del Caribe, sugería mantener tan sólo tres tribunales asentados en México, Lima y Cartagena. Con un tono simplificador estimaba que, excepción hecha de Lima y México, todos los distritos audienciales tenían muy pocos lugares de españoles de jurisdicción y estaban tan despoblados de vecinos que no era infrecuente ver a "los oidores diciendo cuentos en los estrados" y asistiendo a ellos por hacer tiempo y llevar sus sueldos. Por esta razón, afirmaba que como "la causa ha cesado debe cesar también su efecto", siendo preciso suprimir ocho Audiencias innecesarias. Esto reportaría un ahorro de 117.000 ducados a la Real Hacienda, se adecuaría la organización de los citados tribunales a la distribución demográfica y se conseguiría tener una comunicación relativamente fluida con la Corte en virtud de la organización del sistema de flotas y galeones. Así, mientras las dos Audiencias radicadas en las capitales virreinales tenían razones suficientes para preservarse, la instalación de una nueva en Cartagena se explicaba por la importancia que, como centro comercial, poseía esa ciudad. Pero además

64 Ibidem, pp. 79-97. Esta cifra es exagerada ya que Gaytán aumenta el número de Cajas Reales indianas y la cuantía de los sueldos.

65 Ibidem, pp. 76-79. 
habría que señalar que, aparte de ser una forma de ahorrar un gasto innecesario, sería una manera de evitar agravios por parte de los oidores, quienes, según nuestro autor, hacían lo que querían porque no había nadie que se atreviera contra ellos, por ser "los más hechuras y deudos de los consejeros y secretarios de Indias". ${ }^{66}$

Basándose en un argumento semejante, Gaytán considera pertinente una revisión de las jurisdicciones de algunas gobernaciones americanas por resultar las existentes poco adecuadas a las nuevas circunstancias. Así, las gobernaciones de Trinidad, Guayana y Cumaná debían agregarse a la de Margarita y las de Santa Marta y Cartagena debían fusionarse en una sola. Del mismo modo, las gobernaciones de Cuba y Florida tenían que agruparse en una misma jurisdicción. Esto conseguiría una mejor defensa del territorio y, fundamentalmente, excusaría gastos innecesarios. Con este mismo afán ahorrador, proponía descargar las arcas reales mediante el pago de los sueldos de los gobernadores, e incluso de los virreyes, por parte de los propios de los Ayuntamientos. ${ }^{67}$

Las Reglas establecen una medida de excepción para acabar con el gran desorden en materia de sueldos y oficios en Indias, que Gaytán consideraba la causa principal del consumo de la hacienda que en ellas se producía. En este punto se apoya en varios ejemplos, como en el del cargo de administrador del asiento del tabaco de Cartagena, que se había otorgado a Diego Pinelo; según Gaytán, aunque dicha institución había sido suprimida, Pinelo habría continuado cobrando el sueldo en la Caja de la ciudad. Otro caso era el que se vivía en La Habana con la fundición de artillería; a pesar de haber cesado las fundiciones, los oficiales encargados de ellas continuaban percibiendo los sueldos correspondientes. De esta manera quedaba sancionado el nocivo principio de que "sueldo que se asienta en la Caja Real jamás se borra" ${ }^{68}$

Finalmente, la visita general de las distintas jurisdicciones indianas, disposición adoptada en los primeros años del régimen de Olivares, era el medio elegido por Gaytán para remediar todos estos abusos que representaban una sangría para la Real Hacienda de casi un millón de ducados en gastos innecesarios. ${ }^{69}$

66 Ibidem, pp. 71-76.

67 Ibidem, pp. 104, 108-112.

68 Ibidem, p. 109.

69 Ibidem, pp. 108-112. 


\section{A modo de conclusión}

Luego de trazar este breve esquema del pensamiento de Manuel Gaytán de Torres acerca de la administración indiana es posible asegurar que su principal interés no radica en sus propuestas consideradas de manera concreta. Desde esta perspectiva, algunas de ellas resultan poco originales, desproporcionadamente simples respecto de los problemas que pretenden solucionar, o, incluso, incongruentes entre sí. Tal sería el caso, por ejemplo, de su proyecto de poner en manos de los Ayuntamientos indianos el control de la Real Hacienda y el pago de los sueldos de los gobernadores y los virreyes. De tal forma que, mientras que respecto a los nombramientos de sujetos para servir los cargos de la Monarquía el remedio de Gaytán se resume en un procedimiento centralizado en el rey, para el manejo de la fiscalidad indiana se decanta por una propuesta, bastante incomprensible en el contexto de sus intenciones reformistas, de descentralización en los poderes locales.

En cambio, considero que una de las principales contribuciones del estudio del movimiento arbitrista referido a América y de esta obra en particular, consiste en facilitarnos aproximaciones a las percepciones contemporáneas de los problemas de la Monarquía y al repertorio de remedios concebibles, tanto desde un horizonte intelectual determinado, como desde posiciones, experiencias e intereses concretos. Si por momentos los escritos de Gaytán sobre el gobierno pueden resultar simplistas, ingenuos o poco prácticos, no hay que olvidar que sus propuestas tenían muchos puntos en común con el movimiento reformista encabezado por Olivares. Sólo por mencionar uno de estos puntos, podríamos resaltar que, tanto para Gaytán como para el valido, política y virtud continuaban siendo una díada esencial e ineludible para la conservación de la Monarquía y para su revitalización moral. Es decir que los textos de este arbitrista expresaban y reproducían ideas y esquemas de gran aceptación en el complejo cultural y político de su época.

Asimismo, su caso revela una de las facetas funcionales del arbitrismo, al presentarlo como un modo potencial de promoción en la administración. Como se ha visto, este tipo de escritos brindaban la oportunidad a los memorialistas de presentarse como dueños del saber y la capacitación necesarios para formar parte de la elite administrativa de la Monarquía. 
Por lo tanto, la profundización en el conocimiento del arbitrismo según los lineamientos señalados en este artículo contribuirá notablemente a la comprensión de la cultura y de las prácticas políticas de Antiguo Régimen en el contexto hispánico en general, y en la América colonial en particular, resaltando el hecho de que ambos son fenómenos históricamente encuadrados. Esto cobra todo su sentido si se tiene presente que el reconocimiento relativamente reciente de la alteridad y de la distancia que separa dicha cultura y dichas prácticas con las de los sistemas políticos surgidos con la modernidad, ha dado lugar a una reinterpretación de esa época histórica que constituye uno de los mayores desafíos para la renovación de la Historia Política americana. 